\title{
Seasonal variation of lipophilic constituents in roots of Echinacea purpurea and E. pallida
}

Maria O. Thomsen ${ }^{1}$, Lars P. Christensen ${ }^{2}$ and Kai Grevsen ${ }^{1}$

${ }^{1}$ Aarhus University, Department of Food Science, Kirstinebjergvej 10, Aarslev, Denmark.

2University of Southern Denmark, Department of Chemical Engineering, Biotechnology and Environmental Technology, Niels Bohrs Allé 1, Odense, Denmark

\section{Introduction}

Echinacea purpurea and E. pallida are widely used for the unspecific enhancement of the immune system. Lipophilic constituents such as alkamides and ketoalkenes/ketoalkynes are believed to be among the active metabolites in E. purpurea and E. pallida, respectively, with the highest concentrations in roots.

This work investigated the impact of harvest season on lipophilic constituents in roots grown for four to five years in a north European climate.
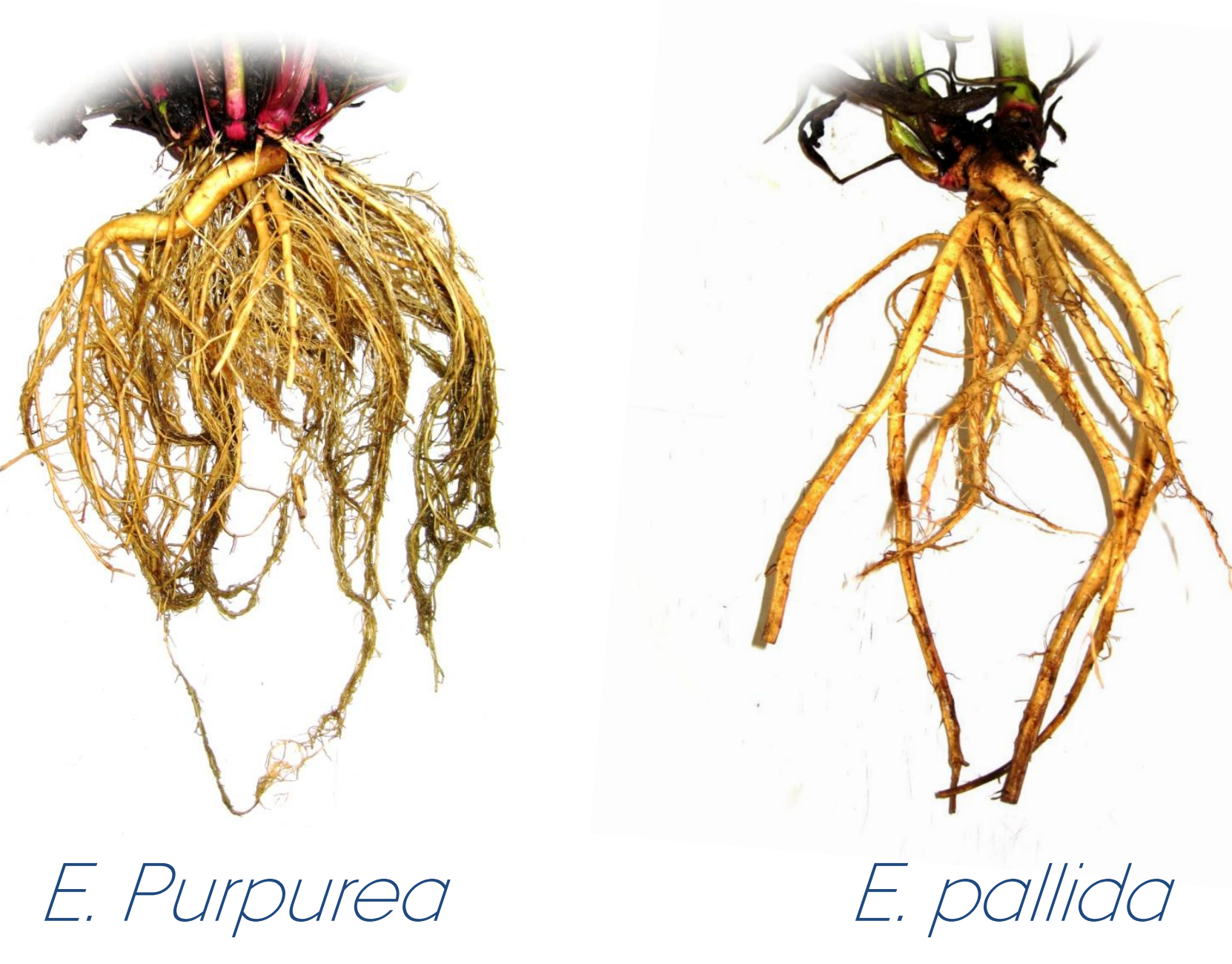

Method

Five roots of 4 to 5 year old E. pallida (Nutt) Nutt. and seven roots of 3 to 4 year old E. purpurea (L.) Moench, each from the same population, were collected throughout one year from early winter 2009 to fall 2010.

Lipophilic constituents were extracted from freeze dried roots with ethanol-water (70:30). Extractions were performed in three replicates and analysed by HPLC-PDA.
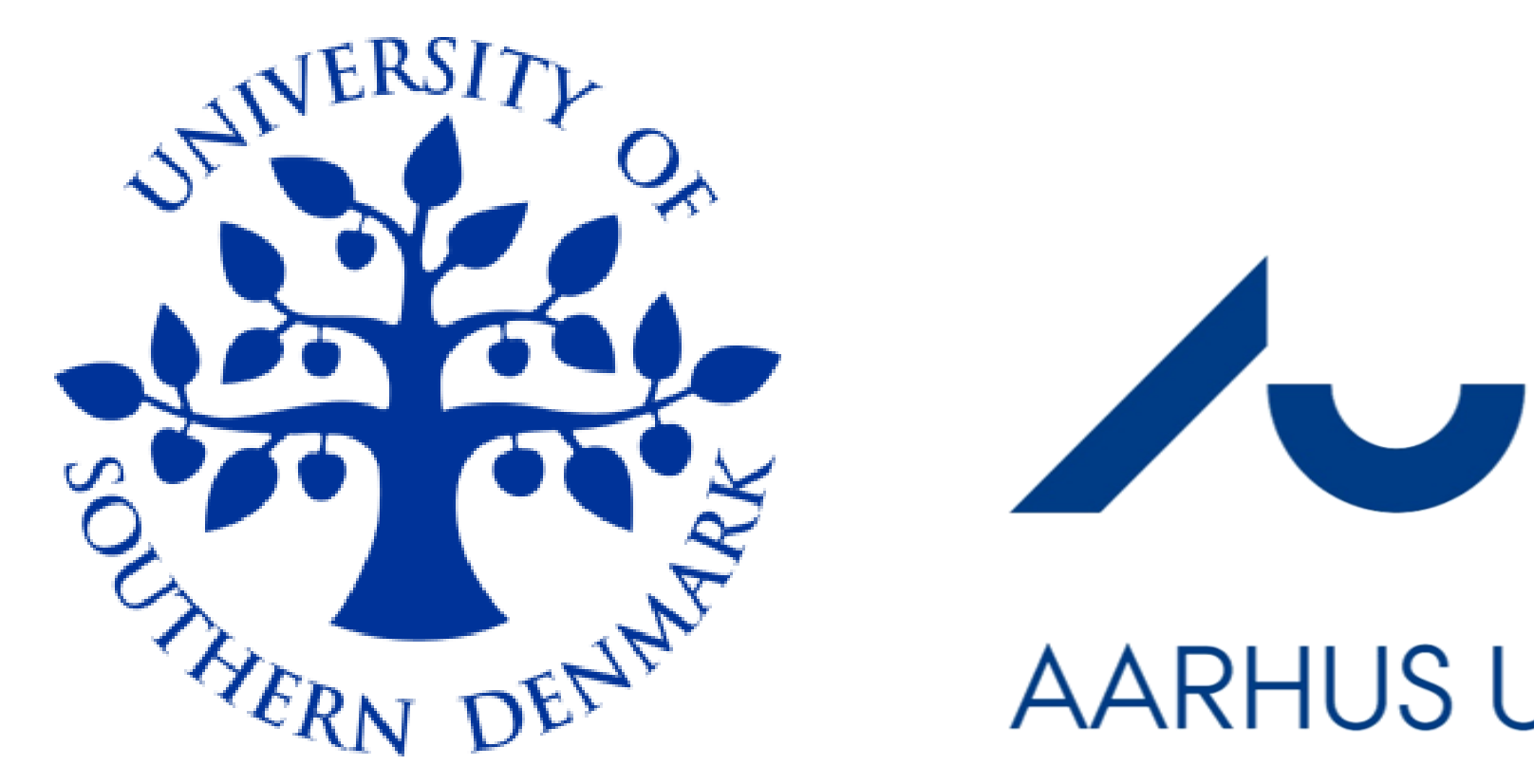

AARHUS UNIVERSITY

\section{Results}

The alkamides in E. purpurea could be separated into two groups. One group (1,2 and 6 in Fig. 1) had the significantly highest concentrations during summer (D), when the soil temperature was high. The other group (35. Fig. 1) had a significantly higher concentrations when the temperature was just above $0^{\circ} \mathrm{C}$ in early spring (B).

The significantly highest concentrations of ketoalkenes/ketoalkynes and alkamides in E. pallida roots (Fig. 1) were found, when the soil temperature was just above $0^{\circ} \mathrm{C}$ in early spring (B), except for compound 9 which did not show statistical differences.
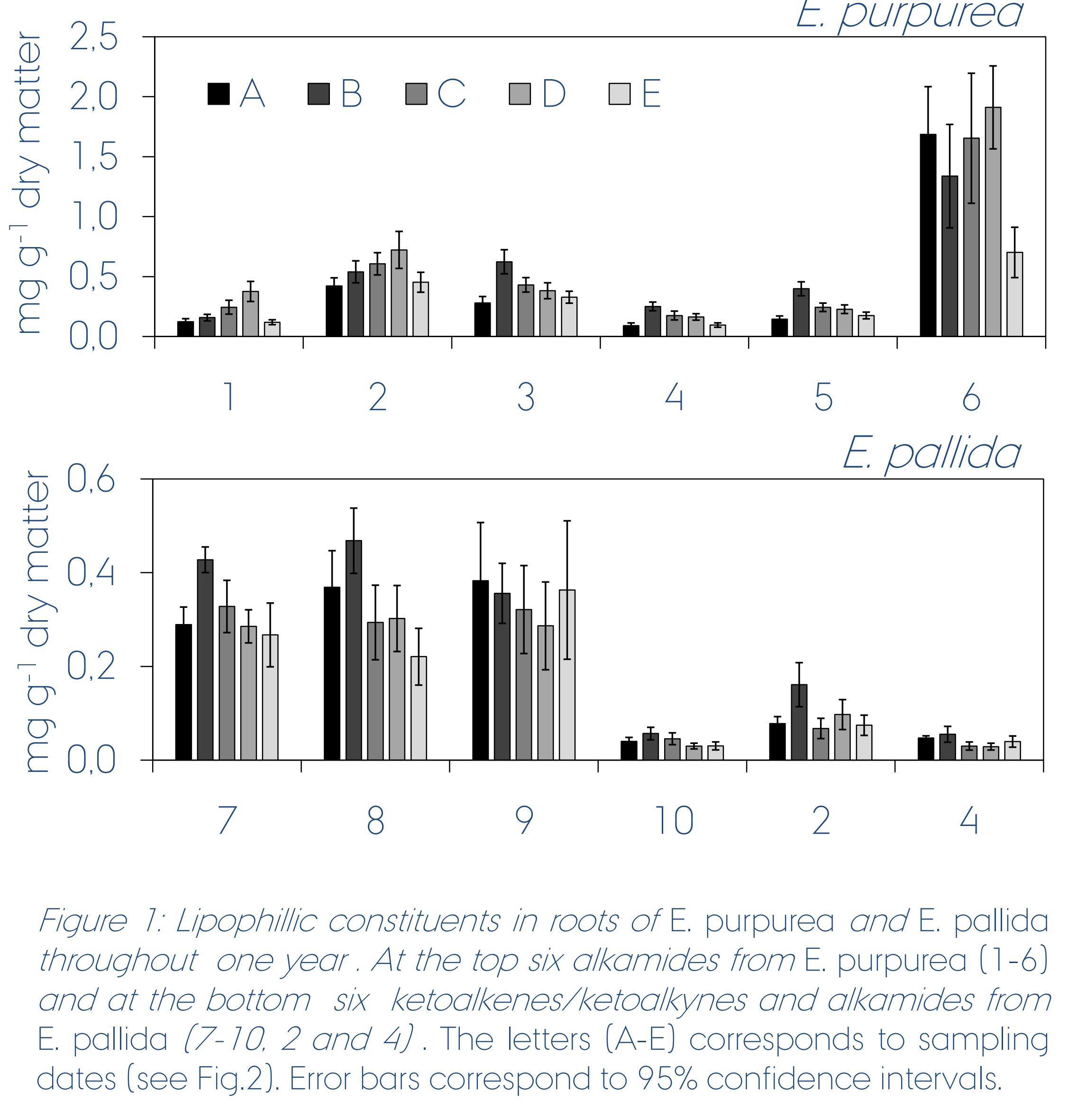
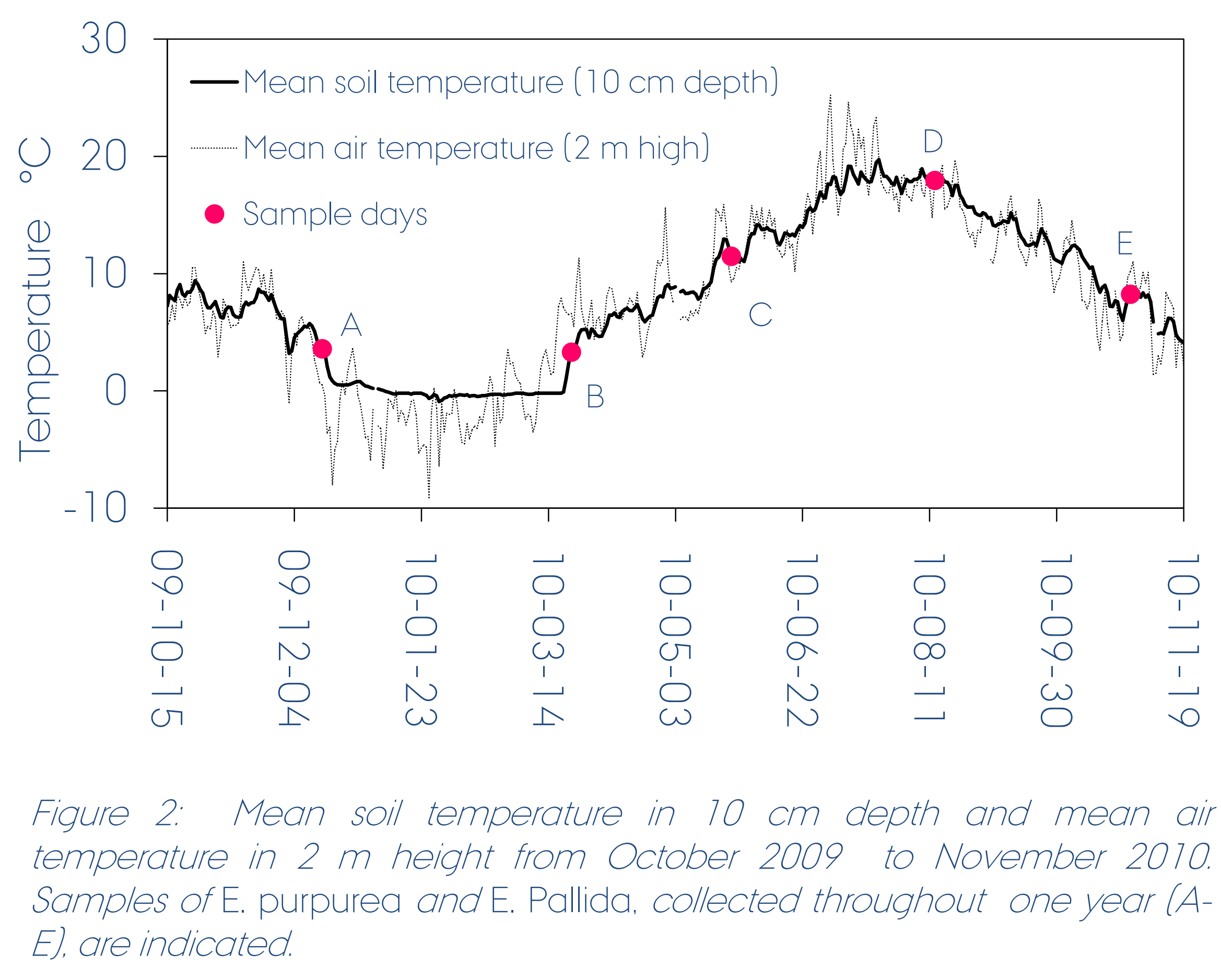

Undeca-2E,4Z-dien-8, 10-diynoic acid isobutylamide Undeca-2Z,4E-dien-8,10-diynoic acid isobutylamide 3 Dodeca-2E,4Z-dien-8,10-diynoic acid isobutylamide Undeca-2E,4Z-dien-8, 10-diynoic acid 2-methylamide Dodeca-2E,4Z-dien-8, 10-diynoic acid 2-methylamide 6 Dodeca-2E,4E,8Z,10E/Z-tetraenoic acid isobutylamide Tetradeca-8Z-ene-1 1.13-diyn-2-one 9 Pentadeca-8Z, 13Z-dien-1 1 -yn-2-one 10 Pentadeca-8Z,1 1Z,13E-trien-2-one

\section{Conclusion}

The concentration of lipophilic constituents in roots of E. pallida was highest in early spring (B). when the mean soil temperature was just above $0^{\circ} \mathrm{C}$. whereas this was only the case for some lipophilic constituents in E. Purpurea. One group of alkamides in roots of E. purpurea showed the highest concentration in midsummer (D). 